\title{
Karakter Agronomi dan Daya Hasil Tiga Klon Ubi Jalar Ungu (Ipomoea batatas) di Lahan Masam Lampung
}

\section{Character Agronomi and Strength Yield Three Clones Purple Sweet Potato (Ipomoea batatas) in The Acidic Soil Lampung}

\author{
Ratna Dewi dan Hery Sutrisno \\ Politeknik Negeri Lampung Jln. Soekarno- Hatta, Rajabasa Bandar Lampung
}

\begin{abstract}
Sweet potato is one of the alternative foods of rice that can be grown on a variety of soil conditions and almost fits on all altitude. Sweet potato clones with purple tuber contains anthocyanins which are antioxidants for our bodies. Purple sweet potato clones include: Varieties Ayamurasaki, Antin and local Purple Lampung. Ayamurasi is the introduction of the Japanese varieties, Antin was the result of the assembly and Purple Balitkabi Malang local is local varieties Lampung. To know the character of the growth and yield of sweet potato are three clones in acidic soil, it is necessary to test for these clones. This study was conducted at California State-owned plantation practices Lampung from May to November in 2011. The study used a randomized complete group (RKTL). Three clones of sweet potato used is Ayamurasaki Clones, Clone-1 and Clone Antin Local Purple Lampung, each repeated 4 times, so there are 12 experimental units. The data were analyzed by analysis of variance, and to know the difference between treatments done LSD a real level of 5\% respectively. The conclusion of this research are: 1. There are differences between clones Antin agronomic character-1, Ayamurasaki, and Purple Local Lampung, 2. In acidic soil Lampung, Antin-1 clones are not resistant to stem borer attack and ladybugs (Omphisa anastomasalis), 3. Local Purple Clones Lampung has advantages in production and pest resistance, and has a good adaptation to the acidic soil Lampung, 4. Local Purple Lampung clones producing the highest production which amounted to $878.33 \mathrm{~g}$ per plant, followed by clones and clones Ayamurasaki Antin-1, each of which produces a production of $590 \mathrm{~g}$ and $166.67 \mathrm{~g}$ per plant
\end{abstract}

Keywords: Character, Purple sweet potato, Acidic soil

Diterima: 29-11-2013, disetujui: 17-01-2014

\section{PENDAHULUAN}

Di Indonesia, 89\% produksi ubi jalar digunakan sebagai bahan pangan dengan tingkat konsumsi 7,9 kg/kapita/tahun, sedangkan sisanya dimanfaatkan sebagai bahan baku industri, terutama saus, dan pakan ternak. Selama ini penggunaan ubi jalar sebagai bahan pangan masih terbatas dalam bentuk makanan tradisional, seperti ubi rebus, ubi goreng, kolak, gethuk, timus, dan keripik, sehingga citranya rendah. Setelah tahun 2000-an , pemanfaatan ubi jalar sebagai bahan pangan mulai bervariasi (Soplanit dan Yusuf, 2007). 
Senyawa antosianin yang terdapat pada ubi jalar ungu berfungsi sebagai antioksidan dan penangkap radikal bebas, sehingga berperan dalam mencegah terjadinya penuaan, kanker, dan penyakit degeneratif, seperti arteriosclerosis. Selain itu, antosianin juga memiliki kemampuan sebagai anti mutagenik dan antikarsinogenik terhadap mutagen dan karsinogen yang terdapat pada bahan pangan dan produk olahannya, mencegah gangguan fungsi hati, antihipertensi, dan menurunkan kadar gula darah (antihiperglisemik) (Santoso et al. 1996).

Klon ubi jalar ungu antara lain: Ayamurasaki, Antin dan Ungu lokal. Ayamurasi merupakan Varietas introduksi dari Jepang, Antin merupakan hasil rakitan dari BALITKABI Malang dan Ungu lokal merupakan Varietas lokal Lampung. Dengan meningkatnya permintaan terhadap ubi jalar kaya akan antosianin untuk bahan baku industri pangan maupun pengobatan, maka perlu dikembangkan berbagai varietas unggul ubi jalar warna ungu agar dapat memberikan banyak pilihan bagi petani dan konsumen. Untuk mengetahui karakter pertumbuhan dan daya hasil tiga klon ubi jalar tersebut di lahan masam Lampung, maka perlu dilakukan pengujian terhadap klon-klon tersebut.

\section{METODE}

\section{Tempat dan Waktu Penelitian}

Penelitian ini dilaksanakan di kebun praktik milik Politeknik Negeri Lampung mulai bulan Mei sampai dengan November tahun 2011. Bahan yang digunakan dalam penelitian ini antara lain bibit ubi jalar klon Ayamurasaki, Antin-1, dan Ungu lokal Lampung, pupuk urea, SP36, KCL, kompos jerami. Sedangkan alat yang digunakan yaitu: cangkul, gunting setek, kored, ember, timbangan, tampah, sabit, tali rafia, roll meter

Penelitian ini menggunakan rancangan kelompok teracak lengkap (RKTL). Tiga klon ubi jalar yang digunakan adalah Klon Ayamurasaki, Klon Antin-1 dan Klon Ungu Lokal Lampung, masing-masing diulang 4 kali, sehingga terdapat 12 satuan percobaan.

\section{Pelaksanaan Penelitian}

Persiapan bibit dimulai dengan menunaskan umbi untuk memperoleh setek tunas awal. Dari setek tunas awal yang dihasilkan oleh umbi, setek-setek pucuk tersebut diperbanyak untuk menghasilkan setek yang akan digunakan sebagai bahan tanam. Persiapan lahan tanam dimulai dengan mengolah tanah yaitu dicangkul satu kali, selanjutnya digemburkan. Tahap berikutnya adalah pembuatan petak-petak percobaan, dengan ukuran 4 x 3m sebanyak 12 petak. Pada setiap petak dibuat guludan-guludan selebar 1 × $4 \mathrm{~m}$, sehingga pada setiap petak terdapat 3 guludan. Guludan dibuat dengan tinggi sekitar $40 \mathrm{~cm}$.

Bibit yang berasal dari setek pucuk, ditanam di atas guludan dengan jarak tanam di dalam guludan $25 \mathrm{~cm}$ dan jarak tanam antar guludan $100 \mathrm{~cm}$ sesuai dengan jarak antar guludan. Bibit ditanam dengan menancapkan bagian pangkal setek miring ke kanan sedalam sepertiga dari panjang setek. Pupuk SP36 dicampur dengan $\mathrm{KCl}$ masing-masing dengan dosis $150 \mathrm{~kg}$ dan $100 \mathrm{~kg}$ per hektar dipupukkan secara alur dengan jarak dari barisan tanaman $7 \mathrm{~cm}$ sepanjang guludan. Pupuk Urea setengah dosis yaitu $50 \mathrm{~kg}$ per hektar diberikan setelah tanaman berumur 2 minggu setelah tanam, dimana akar tanaman sudah mampu menyerap unsur hara dan air. Pemupukan urea berikutnya dilakukan setelah tanaman berumur 45 hari setelah tanam dengan dosis setengah sisanya (50 kg per hektar). 
Ratna Dewi dan Hery Sutrisno: Karakter Agronomi dan Daya Hasil Tiga Klon Ubi Jalar Ungu...

Pengendalian gulma dilakukan pada saat tanaman berumur 30 hari setelah tanam dengan dikored dan sekaligus dilakukan pembalikan batang, agar pada setiap buku yang bersentuhan dengan tanah tidak membentuk umbi.

Pengairan diberikan apabila tidak ada hujan, dengan springkler hingga tanah cukup lembab dan pengendalian hama dan penyakit dilakukan apabila terlihat gejala serangan, baik terhadap daun maupun umbinya.

Pengamatan dilakukan dengan mengambil 5 tanaman sampel secara acak, kemudian diratarata.Parameter yang diamati dan diukur dalam penelitian ini antara lain adalah:1) Karakter agronomi dari tiga klon ubi jalar. Dilakukan dengan cara mengamati tipe pertumbuhan, bentuk dan warna dari daun, batang, dan umbi; 2) Jumlah umbi layak konsumsi per tanaman (buah). Dilakukan dengan menghitung jumlah umbi layak konsumsi per tanaman yang dilakukan pada saat panen; 3) Berat umbi per tanaman $(\mathrm{g})$. Dilakukan dengan cara menimbang berat umbi per tanaman yang dilakukan pada saat panen; 4) Diameter umbi. Dilakukan dengan mengukur diameter setiap umbi per tanaman, kemudian dirata-rata; 5) Panjang umbi. Dilakukan dengan mengukur panjang setiap umbi per tanaman, kemudian dirata-rata

Data hasil pengamatan dianalisis dengan sidik ragam, dan untuk mengetahui perbedaan antar perlakuan dilakukan uji BNT dengan taraf nyata masing-masing $5 \%$.

\section{HASIL DAN PEMBAHASAN}

\section{Karakter agronomi tiga klon ubi jalar ungu di lahan masam Lampung}

Hasil pengamatan menunjukkan terdapat perbedaan karakter agronomi pada tiga klon ubi jalar ungu. Adapun perbedaan dari ketiga klon ubi jalar ungu tersebut dapat dilihat pada Tabel 1

Tabel 1. Karakter agronomi tiga klon ubi jalar ungu di lahan masam Lampung

\begin{tabular}{lccc}
\hline Karakter agronomi & Ayamurasaki & Antin-1 & Ungu Lokal Lampung \\
\cline { 2 - 4 } Tipe pertumbuhan & semi kompak & semi kompak & semi kompak \\
Batang & tidak berbulu & berbulu & tidak berbulu \\
Warna batang & ungu di pangkal & hijau keunguan & hijau \\
Warna dominan sulur & hijau & hijau keunguan & hijau \\
Warna buku sulur & hijau & ungu & hijau \\
Bentuk daun & hati & segitiga & segitiga \\
Jumlah cuping daun & - & 3a & 5 \\
Warna daun muda & hijau & ungu kecoklatan & coklat muda \\
Warna daun dewasa & hijau & hijau & hijau \\
Warna tulang daun & hijau & ungu & hijau \\
permukaan bawah & & & \\
Ukuran daun & sedang & sedang & sedang \\
Warna kulit umbi & ungu & putih susu krem & putih \\
Warna daging umbi & ungu & ungu putih & ungu putih \\
\hline
\end{tabular}




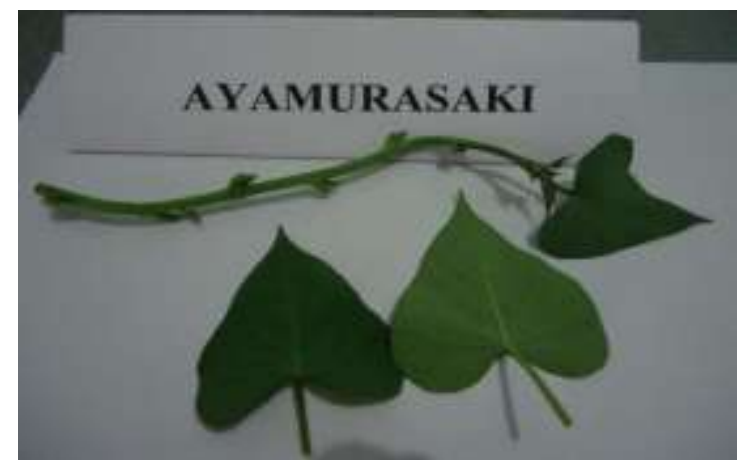

Gambar 1. Daun ubi jalar Ayamurasaki

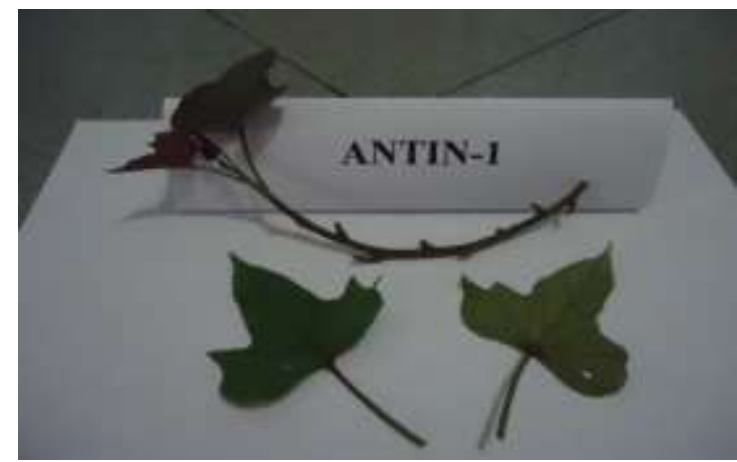

Gambar 3. Daun ubi jalar Antin-1

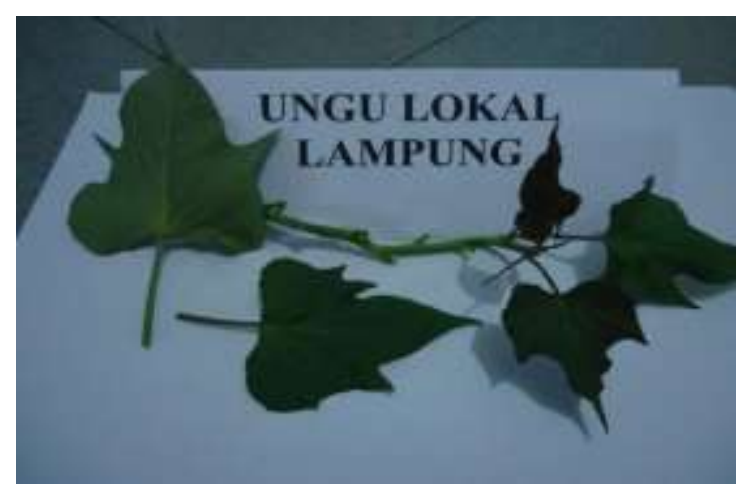

Gambar 5. Daun ubi jalar Ungu Lokal Lampung

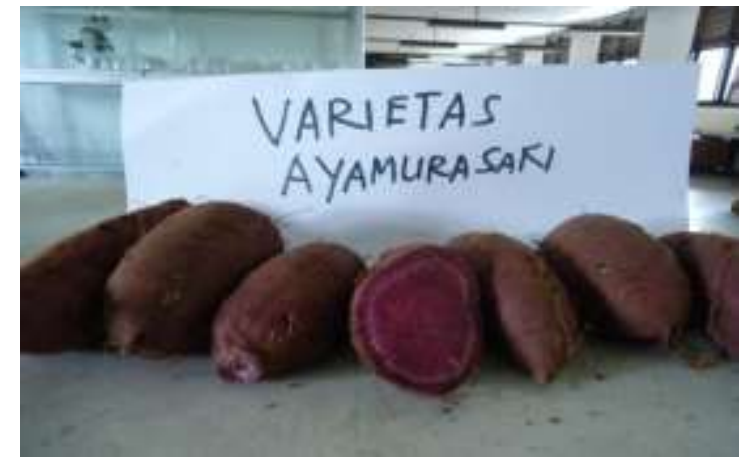

Gambar 2. Umbi ubi jalar Ayamurasaki

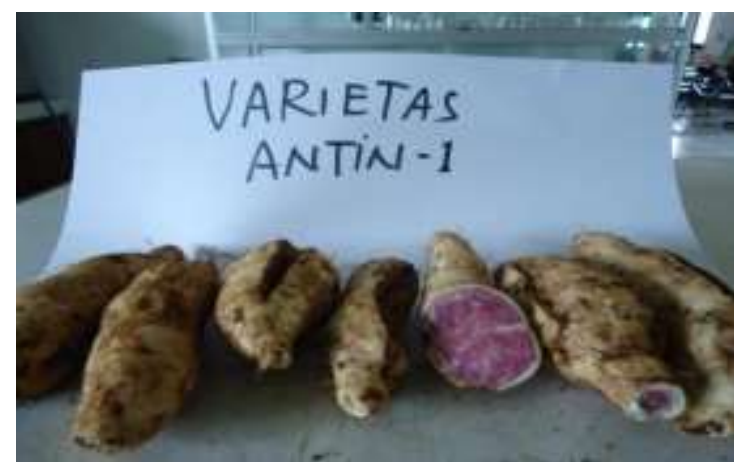

Gambar 4. Umbi ubi jalar Antin-1

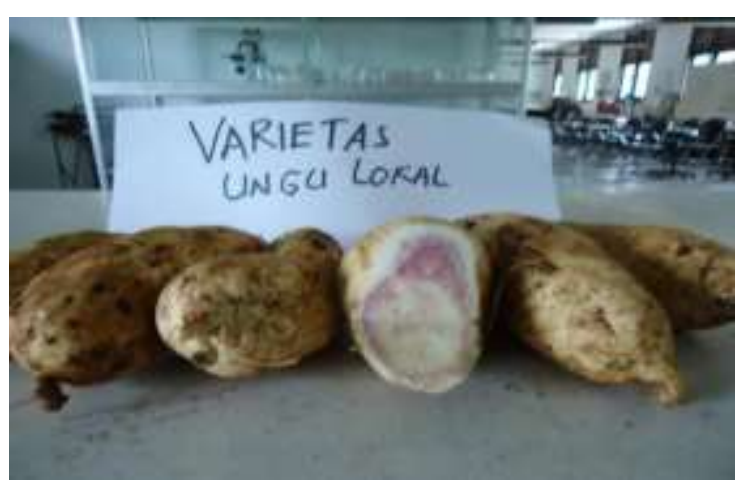

Gambar 6. Umbi ubi jalar Ungu Lokal Lampung

\section{Jumlah umbi per tanaman (buah)}

Hasil analisis ragam menunjukkan bahwa antar Klon Ayamurasaki, Antin-1 dan Ungu Lokal Lampung memberikan pengaruh berbeda tidak nyata terhadap jumlah umbi per tanaman (Tabel 2). Namun jika dilihat dari nilai rata-rata jumlah umbi per tanaman, Klon Ungu Lokal Lampung menghasilkan jumlah umbi yang lebih banyak dibandingkan dengan Klon Ayamurasaki dan Antin-1 yakni 4,67 buah, meskipun berbeda tidak nyata dengan Klon Ayamurasaki yang menghasilkan 3,67 buah, dan Klon Antin-1 yang menghasilkan 3,00 buah (Tabel 3).

\section{Berat umbi per tanaman $(\mathrm{g})$}

Hasil analisis ragam menunjukkan bahwa antar Klon Ayamurasaki, Antin-1 dan Ungu Lokal Lampung memberikan pengaruh sangat nyata terhadap berat umbi per tanaman (Tabel 2). Klon Ungu 
Ratna Dewi dan Hery Sutrisno: Karakter Agronomi dan Daya Hasil Tiga Klon Ubi Jalar Ungu...

Lokal Lampung menghasilkan berat umbi per tanaman terberat yakni 878,33 g. Kemudian diikuti Klon Ayamurasaki menghasilkan 590 g, dan Klon Antin-1 menghasilkan 166,67 g (Tabel 3).

\section{Diameter umbi (mm)}

Hasil analisis ragam nenunjukkan bahwa antar Klon Ayamurasaki, Antin-1 dan Ungu Lokal Lampung memberikan pengaruh yang tidak nyata terhadap diameter umbi per tanaman (Tabel 2). Namun jika dilihat dari nilai rata-rata diameter umbi, Klon Ungu Lokal Lampung menghasilkan diameter umbi yang lebih besar dibandingkan dengan Klon Ayamurasaki dan Antin-1 yakni 51,13 mm, meskipun berbeda tidak nyata dengan Klon Ayamurasaki yang menghasilkan 45,89 mm, dan Klon Antin-1 yang menghasilkan 32,17 mm (Tabel 3).

\section{Panjang umbi (cm)}

Hasil analisis ragam nenunjukkan bahwa antar Klon Ayamurasaki, Antin-1 dan Ungu Lokal Lampung memberikan pengaruh nyata terhadap panjang umbi per tanaman (Tabel 2). Klon Ayamurasaki menghasilkan rata-rata panjang umbi $130,70 \mathrm{~mm}$, tidak berbeda nyata dengan Klon Ungu Lokal Lampung yang menghasilkan rata-rata panjang umbi $140,10 \mathrm{~mm}$, namun berbeda nyata dengan Klon Antin-1 yang menghasilkan rata-rata panjang umbi 102,54 (Tabel 3).

Tabel 2. Hasil analisis ragam (uji F) pada tiga klon ubi jalar ungu terhadap jumlah umbi per tanaman, berat umbi per tanaman, diameter umbi dan panjang umbi

\begin{tabular}{lccc}
\hline \multicolumn{1}{c}{ Variabel pengamatan } & F-hitung & F-tabel & $\begin{array}{c}\text { Koefisien keragaman } \\
(\%)\end{array}$ \\
\hline Jumlah umbi per tanaman (buah) & $4,75 \mathrm{~ns}$ & 6,94 & 17,65 \\
Berat umbi per tanaman $(\mathrm{g})$ & $32,88^{*}$ & 6,94 & 19,84 \\
Diameter umbi (mm) & $6,47 \mathrm{~ns}$ & 6,94 & 15,48 \\
Panjang umbi (mm) & $7,74^{*}$ & 6,94 & 9,78 \\
\hline
\end{tabular}

Tabel 3. Hasil uji BNT pada tiga klon ubi jalar ungu terhadap jumlah umbi per tanaman, berat umbi per tanaman, diameter umbi dan panjang umbi

\begin{tabular}{lcccc}
\hline Jenis Varietas Ungu (V) & $\begin{array}{c}\text { Jumlah umbi } \\
\text { pertanaman } \\
\text { (buah) }\end{array}$ & $\begin{array}{c}\text { Berat umbi per } \\
\text { tanaman }(\mathrm{g})\end{array}$ & $\begin{array}{c}\text { Diameter umbi } \\
(\mathrm{mm})\end{array}$ & $\begin{array}{c}\text { Panjang umbi } \\
(\mathrm{mm})\end{array}$ \\
\hline V1 = Ayamurasaki & $3,67 \mathrm{a}$ & $590,00 \mathrm{~b}$ & $45,89 \mathrm{a}$ & $30,70 \mathrm{a}$ \\
V2 = Antin-1 & $3,00 \mathrm{a}$ & $166,67 \mathrm{c}$ & $32,17 \mathrm{a}$ & $102,54 \mathrm{~b}$ \\
V3 = Ungu Lokal Lampung & $4,67 \mathrm{a}$ & $878,33 \mathrm{a}$ & $51,13 \mathrm{a}$ & $140,10 \mathrm{a}$ \\
\hline
\end{tabular}

Hasil pengamatan menunjukkan adanya perbedaan karakter agronomi antar ketiga klon ubi jalar yang ditanam di lahan masam Lampung, terutama pada batang, warna batang, warna dominan sulur, warna buku sulur, warna daun muda, bentuk daun, jumlah cuping pada daun, warna kulit umbi dan warna daging umbi (Tabel 1). Hal ini sangat berhubungan dengan sifat genetik dari masingmasing varietas yang dibawa oleh gen.

Hasil analisis uji BNT (Tabel 3) menunjukkan pada setiap variabel pengamatan, Klon Antin-1 memberikan hasil yang lebih rendah bila dibandingkan dengan Klon Ayamurasaki dan Klon Ungu Lokal Lampung. Hal ini terkait dengan adanya serangan kepik dan ulat penggerek pada batang Klon Antin-1(Gambar 7 dan 8), sedangkan Klon Ayamurasaki dan Ungu Lokal Lampung tidak mengalami kendala yang berarti dalam pertumbuhannya. 


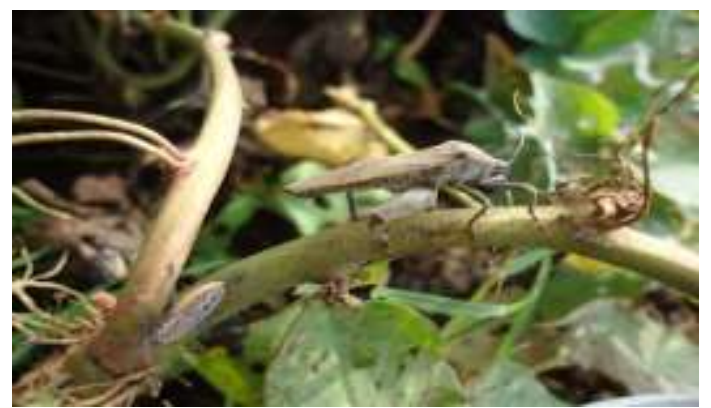

Gambar 7. Kepik pada batang Antin-1
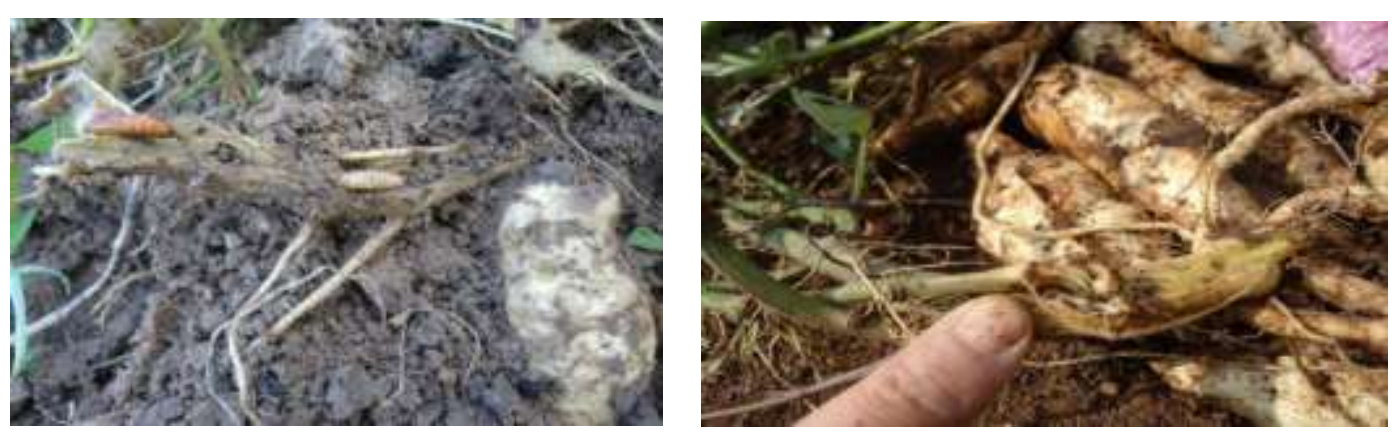

Gambar 8. Batang ubi jalar Antin-1 yang terserang ulat penggerek

Serangan kepik yang cukup banyak pada Klon Antin-1 mungkin dikarenakan batang Antin-1 yang berbulu, sehingga kepik lebih nyaman berdiam diri dan merusak batang dengan cara menusuk dan mengisap cairan sel pada batang. Hamim (2007) menyatakan bahwa bulu-bulu daun memiliki kemampuan yang baik dalam mengurangi besarnya energi cahaya yang sampai ke permukaan daun dan dalam keadaan kekeringan adanya bulu-bulu daun dapat menurunkan laju penguapan daun. Dari pernyataan Hamim (2007) di atas, dimungkinkan keadaan yang sama terjadi juga pada organ batang yang berbulu, sehingga keberadaan kepik lebih banyak pada batang yang berbulu.

Adanya serangan kepik mengakibatkan jaringan pada batang mengalami kerusakan, sehingga unsur hara/nutrisi dan air dari tanah yang disalurkan menuju source (sumber) dalam hal ini daun, menjadi tidak optimal. Selain serangan kepik, serangan ulat penggerek batang (Omphisa anastomasalis) memiliki pengaruh yang sangat besar terhadap menurunnya produksi ubi jalar. Rukmana (1997) menyatakan bahwa stadium hama penggerek batang yang merusak tanaman ubi jalar adalah larva (ulat). Larva (ulat) menyerang dengan cara membuat lubang kecil memanjang pada batang hingga ke bagian umbi. Serangan hama ini dapat mengakibatkan pembengkakan pada batang dan di dalam lubang tersebut dapat ditemukan larva (ulat). Selanjutnya dikatakan bahwa tingkat serangan yang berat dapat menurunkan produksi ubi jalar.

Adanya pembengkakan pada batang ubi jalar merupakan adanya indikasi ketidaknormalan/kerusakan pada jaringan yang ada pada batang terutama pada jaringan floem yang sangat berguna dalam proses translokasi fotosintat dari source (sumber) ke daerah penampungan (sink). Keadaan ini menyebabkan suplai asimilat ke umbi (sink) pada ubi jalar tidak optimal.

Menurut Gardner et al. (1998), source (sumber) adalah jaringan yang mensuplai asimilat, organ tanaman yang aktif berfotosintesis adalah daun dan bagian tanaman yang berwarna hijau (yang mengandung klorofil). Sedangkan sink adalah jaringan yang menampung atau menerima asimilat, tetapi tidak aktif berfotosintesis misalnya buah, biji dan umbi. Selanjutnya dikatakan bahwa, kemungkinan ada 3 faktor yang membatasi hasil pada tanaman. Pertama adalah kemampuan tanaman 
Ratna Dewi dan Hery Sutrisno: Karakter Agronomi dan Daya Hasil Tiga Klon Ubi Jalar Ungu...

melakukan fotosintesis sesudah pembungaan. Faktor ini dipengaruhi oleh ukuran yang dinyatakan dengan indek luas daun, ketahanan daun agar tetap hijau dan efisiensi dari sistem fotosintesis. Faktor ini merupakan kemampuan dari penghasil (source). Kedua adalah kemampuan biji dan juga kemampuan bersaing dengan pemakai (sink) yang lain. Ketiga adalah kemampuan dari jaringan pengangkut untuk mengalirkan hasil fotosintesis.

Rendahnya hasil pada Klon Antin-1 bisa disebabkan tanaman tidak dapat menyerap nutrisi dan air secara optimal dikarenakan sel-sel organ batang yang dirusak oleh kepik, juga dikarenakan rusaknya jaringan floem sehingga fotosintat dari source tidak dapat ditranslokasi ke umbi (sink) dengan baik dan adanya persaingan dalam translokasi fotosintat dengan organ tanaman lain (batang) yang membutuhkan untuk pemulihan tubuhnya karena dirusak oleh kepik dan hama penggerek batang.

Hasil analisis BNT (Tabel 3) menunjukkan bahwa Klon Ungu Lokal Lampung memberikan hasil yang paling baik pada semua variabel pengamatan. Hal ini menunjukkan bahwa Klon Ungu Lokal Lampung merupakan klon unggul di daerah Lampung. Unggul dalam hal ketahanan terhadap penyakit maupun produksi, serta memiliki adaptasi yang baik terhadap lahan masam di Lampung.

\section{KESIMPULAN}

Terdapat perbedaan Karakter agronomi antara Klon Antin-1, Ayamurasaki, maupun Ungu Lokal Lampung. Pada lahan masam Lampung, Klon Antin-1 tidak tahan terhadap serangan kepik dan penggerek batang (Omphisa anastomasalis). Klon Ungu Lokal Lampung memiliki keunggulan dalam produksi dan ketahanan. Terhadap hama, serta memiliki adaptasi yang baik pada lahan masam Lampung. Klon Ungu Lokal Lampung menghasilkan produksi paling tinggi yakni sebesar 878,33 g per tanaman, kemudian diikuti oleh Klon Ayamurasaki dan Klon Antin-1 yang masing-masing menghasilkan produksi sebesar $590 \mathrm{~g}$ dan 166,67 g per tanaman.

\section{DAFTAR PUSTAKA}

Gardner, F.P., R.B. Pearce, dan R.L. Mitchell. 1998. Fisiologi Tanaman Budidaya. Diterjemahkan oleh Herawati Susilo. UI-Press.Jakarta

Hamim. 2007. Materi Pokok Fisiologi Tumbuhan. Universitas Terbuka. Jakarta

Rukmana, R. 1997. Ubi Jalar, Budidaya dan Paska Panen. Penerbit Kanisius. Yogyakarta.

Santoso.B, Soemono,J. Renwarin, dan Sutihani. 1996. Produksi Ubi jalar dan Kedelai dalam Sistem Tumpangsari. HIPHERE: 1(1): 15-22. Pusat Studi Ubi-ubian. Universitas Cendrawasih. Manokwari.

Soplanit, A dan M. Yusuf. 2007. Kajian Pemberian Pupuk Organik terhadap Pertumbuhan dan Produksi Ubi Jalar di Dataran Tinggi Yahukimo. Makalah disampaikan pada Seminar Nasional Balai Pengkajian Teknologi Pertanian Papua Bekerjasama dengan CIP-ACIAR Penda Provinsi Papua, Jayapura. 